\title{
PENGARUH BRAND AWARENESS DAN PERCEIVED QUALITY TERHADAP REPURCHASE INTENTION MELALUI CUSTOMER SATISFACTION PADA PRODUK DBD POWDER MEDAN
}

\author{
Juan Sakti Gultom, T. Lyza Tahura Chairunnisa, Muller Tamba \\ Fakultas Ekonomi dan Bisnis, Universitas Harapan Medan, Program studi Manajemen \\ Email: juansakti62@gmail.com
}

\begin{abstract}
This study was conducted to determine the effect of brand awareness and perceived quality on repurchase intention mediated by customer satisfaction separately or together. The population is taken from customers who come and buy the company's products with an average of 3,250 consumers per month, a sample of 97 respondents drawn based on the slovin formula. Questionnaires are used to collect data with the data source is primary data. Data analysis techniques consist of data quality test, classical assumption test, path analysis and hypothesis testing. This study gives results that partially brand awareness has a positive but not significant effect on customer satisfaction, perceived quality has a positive and significant effect on customer satisfaction. Brand awareness and perceived quality partially have a significant effect on repurchase intention, and customer satisfaction has a positive and significant influence on repurchase intention at DBD Powder Medan. Simultaneously shows that brand awareness and perceived quality simultaneously have a significant effect on customer satisfaction. Brand awareness, perceived quality and customer satisfaction together have a positive and significant effect on repurchase intention in DBD Powder Medan.
\end{abstract}

Keywords: Brand Awareness, Perceived Quality, Customer Satisfaction, Repurchase Intention

\begin{abstract}
Abstrak
Riset dilaksanakan untuk mendapati pengaruh brand awareness dan perceived quality terhadap repurchase intention yang dimediasi oleh customer satisfaction secara terpisah maupun bersama-sama. Populasi diambil dari Pelanggan yang datang dan membeli produk perusahaan dengan rata-rata perbulan sebanyak 3.250 konsumen, sampel sebanyak 97 responden yang ditarik berdasarkan rumus slovin. Kuesioner digunakan untuk mengumpulkan data dengan sumber data berbentuk data primer. uji kualitas data, uji asumsi klasik, analisis jalur dan uji hipotesis merupakan Teknik analisis yang dilaksanakan di riset ini. Penelitian ini memberikan hasil yaitu secara parsial brand awareness berpengaruh positif tetapi tidak signifikan terhadap customer satisfaction, perceived quality berpengaruh positif dan signifikan terhadap customer satisfaction. Brand awareness dan perceived quality secara parsial memberikan pengaruh signifikan terhadap repurchase intention, dan customer satisfaction memberikan pengaruh positif dan signifikan terhadap repurchase intention di DBD Powder Medan. Secara simultan menunjukkan bahwa brand awareness dan perceived quality serempak pengaruh signifikan pada customer satisfaction. Brand awareness, perceived quality dan customer satisfaction bersama-sama pengaruh positif dan signifikan terhadap repurchase intention di DBD Powder Medan.

Kata kunci: Brand Awareness, Perceived Quality, Customer Satisfaction, Repurchase Intention

\section{Pendahuluan}

Persaingan bisnis saat ini terutama pada bidang minuman cepat saji di kota Medan cukup pesat dimana semakin banyak

perusahaan maupun orang pribadi berupa untuk memasarkan dan memperkenalkan berbagai macam rasa minuman yang beraneka guna memenuhi kebutuhan
\end{abstract}


masyarakat yang berbeda satu sama lainnya.

Kondisi ini dapat ditemui pada beberapa lokasi strategis di Kota Medan seperti di beberapa Mall, supermarket, minimarket maupun perumahan komplek semakin banyak orang yang menjual minuman dengan berbagai pilihan sehingga konsumen bebas memilih rasa dan kenikmatan yang diinginkannya. Perusahaan yang mampu memuaskan konsumen sesuai dengan pengharapan dan keinginannya, maka hal ini akan mempersembahkan value added dan keunggulan spesial bagi produk perusahaan untuk dilirik dan diminati oleh calon konsumen lainnya dan juga pelanggan akan semakin bertambah sehingga keinginan untuk membeli ulang atas produk tersebut akan dilakukan secara berkesinambungan.

Konsumen akan melakukan pembelian atas suatu produk perusahaan bila dalam pikiran konsumen telah melekat merek yang sudah dikenalnya dan terbiasa mengkonsumsi produk tersebut dalam kebutuhan seharihari. Kesadaran seorang konsumen atas suatu merek produk turut menjadi salah satu pertimbangan bagi konsumen apakah mau membeli ataupun tidak produk tersebut. Sebuah brand yang mampu mempertahankan imagenya diingatan konsumen secara statis menandakan bahwa Brand awarenessnya tinggi. (Bimantari,
2018). Pembeli yang merasa membutuhkan barang yang sebanding akan dengan cepat mengingat kembali merek yang dirujuk sehingga di pemikiran mereka akan segera membayangkan hasil dari merek tersebut. Dengan cara ini, brand awareness secara bersamaan menjunjung tinggi kesan barang serupa dalam kepribadian pembeli untuk membeli kembali barang yang telah mereka beli dan habiskan sebelumnya.

Disisi lain, upaya yang dapat dilaksanakan oleh perusahaan guna menumbuhkan keinginan membeli dalam diri pembeli yakni dengan memberikan kepuasan kepada konsumen secara maksimal sehingga dapat mempermudah dan memperkuat diri konsumen untuk membeli produk tersebut. Hidayah dan Anjarwati (2018), menjelaskan bahwa kepuasan merupakan rasa senang atau kekecewaan dari seorang yang muncul diakibatkan oleh adanya bandingan kinerja yang dianggap bahwa produk dan jasa sesuai atau berbeda dengan bayangan atau ekspektasi mereka. apabila kinerja sesuai dengan ekspektasi maka pembeli akan terpuaskan. Hal ini juga akan memberikan keuntungan dan keunggulan bagi perusahaan karena pelanggan akan tetap loyal pada produk perusahaan dan tidak akan pindah pada produk pesaingnya meskipun dapat 
memberikan manfaata produk yang hampir sama. Konsumen yang merasa puas setelah mengkonsumsi produk perusahaan akan menunjukkan sikap dan perilaku yang menyenangkan karena apa yang diespektasikan dari produk tersebut ternyata sesuai dengan bayangannya.

\section{Tinjauan Pustaka}

\section{Brand Awareness}

$$
\text { Eliasari dan Sukaatmadja }
$$

(2017:6625), Brand Awareness adalah kapasitas pembeli yang mungkin untuk merasakan dan mengenang kembali brand sebagai komponen dari barang dengan brand yang bersangkutan. Brand Awareness memerlukan cakupan yang terus-menerus dari sentimen yang dipertanyakan bahwa brand tertentu sudah diketahui sebelumnya, yang selanjutnya pembeli menerima barang itu adalah brand utama dalam kelompok barang.

\section{Perceived Quality}

Bimantari (2019:199), persepsi kualitas adalah penilaian pembeli atas kelaziman atau keunggulan barang secara umum. Penilaian ini dilakukan tergantung pada penilaian umum diantara yang didapat dan dirasakan dibandingkan dengan apa yang diinginkan secara umum. Perceived quality adalah pilihan dan kesan keseluruhan yang diklaim oleh suatu barang atau administrasi bila dibandingkan dengan yang lain. Barang atau administrasi yang menikmati manfaat langsung yang tidak dimiliki oleh barang atau administrasi pembanding dapat dikatakan berkualitas tinggi.

\section{Customer Satisfation}

Hidayah dan Anjarwati (2018:4), kepuasan konsumen adalah tahap penilaian pascapemanfaatan yang dipilih pada dasarnya memenuhi atau melampaui asumsi. sedangkan muncul ketidakpuasan ketika hasil (results) tidak sama dengan asumsi. Akomodasi yaitu satu dari pendorong pemenuhan dan merupakan satu dari rekomendasi dalam memakai suatu barang atau administrasi.

\section{Repurchase Intention}

Bimantari (2019:198), dalam penelitian dapat disampaikan bahwa niat digambarkan dengan adanya inspirasi individu untuk suatu rasa atau pengaturan dengan sadar untuk melakukan gerakan praktik tertentu. Inspirasi ini ada sehingga dapat mendorong tujuan pembelian dan diakui oleh pembeli untuk melanjutkan aktivitas pembelian.

\section{Hubungan Brand Awareness dengan Repurchase Intention}

Berdasarkan penelitian dilakukan oleh Ilyah, et.al. (2020), dapat disimpulkan bahwa brand awareness yang kuat dalam 
persepsi dan pandangan konsumen akan dapat berpengaruh signifikan terhadap pembelian ulang (Repurchase intention) dalam aktivitas perusahaan. Seirama dengan yang dipublikasikan dalam riset Aquinia \& Soliha (2020), dapat dipublikasikan bahwa semakin kuat dan baik kesadaran merek dalam pandangan konsumen atas produk perusahaan, maka makin besarlah kemauan pembeli untuk melakukan pembelian ulang produk tersebut secara kontiniu di masa akan datang. Dengan itu, dapat disampaikan bahwa pentingnya memberikan kesadaran merek yang tepat dalam pandangan konsumen bahwa produk yang ditawarkan dapat dipercayai dan akan memberikan manfaat dan nilai lebih kepada konsumen bila mengkonsumsinya secara terus menerus. Hal ini akan membuat produk perusahaan banyak diminati oleh konsumen dan keunggulan bersaing dalam aktivitas perusahaan akan lebih baik dibandingkan pesaingnya.

$\mathrm{H}_{1}$ : Brand awarenss berpengaruh terhadap repurchase intention pada DBD Powder Medan.

\section{Hubungan Percieved Quality dengan Repurchase Intention}

Berdasarkan penelitian yang dilakukan Aquinia \& Soliha (2020),dapat disampaikan bahwa dengan persepsi kualitas yang baik dan positif dalam pandangan kosnumen atas produk perusahaan akan semakin besar pengaruh yang diberikan terhadap keingina untuk melakukan pembelian kembali terhadap produk tersebut. Hal serupa juga disampaikan dalam penelitian Wijaksono dan Ali (2019), dapat dipublikasikan bahwa makin tingginya pandangan kualitas dalam pikiran tiap pembeli maka makin besarlah niat dan kemauan pelanggan untuk melaksanakan pembelian yang berulang-ulang terhadap produk perusahaan yang berkontiniu. Dari gambaran penjabaran di atas dapat disampaikan bahwa pentingnya persepsi konsumen atas kualitas produk perusaahaan selama mengkonsumsi produk tersebut sehingga hal ini akan memberikan kesan yang positif dan baik dalam diri konsumen terhadap produk perusahaan.

$\mathrm{H}_{2}$ : Percieved quality berpengaruh terhadap repurchase intention pada DBD Powder Medan.

\section{Hubungan Brand Awareness dengan} Customer satisfaction

Mengacu dari hasil riset yang dilakukan oleh Ilyah, et.al. (2020), dapat disampaikan bahwa Brand Awareness yang kuat dalam diri tiap konsumen dapat berpengaruh signifikan terhadap kepuasan konsumen untuk membeli dan 
mengkonsumsinya. Disamping itu, dalam penelitian Izzudin dan Novandairi (2018), dapat disampaikan bahwa keberadaan kesadaran merek perusahaan bagi konsumen dapat memberikan pengaruh cukup kuat terhadap kepuasan pelanggan untuk dapat berbelanja dan memakai produk tersebut untuk pemenuhan keperluan hidupnya. Dengan demikian, dapat disampaikan bahwa konsumen yang telah memiliki keyakinan dan keperyaan pada suatu merek produk tertentu maka hal ini akan memberikan pengaruh cukup besar terhadap kepuasan konsumen saat menggunakan produk tersebut.

$\mathrm{H}_{3}$ : Brand awarenss berpengaruh terhadap customer satisfaction pada DBD Powder Medan.

\section{Hubungan Percieved quality dengan}

\section{Customer satisfaction}

Dalam penelitian Hidayah dan Anjarwati (2018), dapat disampaikan bahwa persepsi kualitas seorang konsumen dalam menggunakan produk perusahaan akan dapat berpengaruh signifikan terhadap kepuasan yang akan dirasakan nantinya setelah mengkonsumsi produk tersebut. Hasil penelitian yang sama juga dilakukan oleh Izzudin dan Novandairi (2018), dapat disampaikan bahwa semakin baik persepsi kualitas dalam diri konsumen maka akan semakin besar pengaruhnya terhadap kepuasan dalam pandangan konsumen untuk secara rutin dan berkesinambungan menggunakan produk tersebut dari waktu ke waktu. Dengan demikian, dapat disimpulkan bahwa konsumen yang mendapatkan persepsi yang bagus mengenai kualitas produk dan pelayanan dari perusahaan, maka hal ini akan memberikan kepuasan tersendiri dalam diri konsumen selama menggunakan produk yang ditawarkan oleh perusahaan.

$\mathrm{H}_{4}$ : Percieved quality berpengaruh terhadap customer satisfaction pada DBD Powder Medan.

\section{Hubungan Customer satisfaction dengan} Repurchase Intention

Dalam penelitian Tarigan dan Atika (2020), dapat disampaikan bahwa keberadaan kepuasan yang dirasakan konsumen saat menggunakan produk perusaahan pertama sekali akan turut menentukan keputusan konsumen untuk selanjutnya apakah membeli ulang kembali produk tersebut atau tidak. Dari penjelasan diatas dapat disampaikan bahwa pembelian ulang suatu produk perusahaan akan ditentukan sampai seberapa besar kepuasan yang diperoleh konsumen saat menggunakan produk tersebut sehingga semakin besar kepuasan yang berhasil diterima konsumen, 
maka semakin kuat konsumen akan membeli ulang produk tersebut dari waktu ke waktu di masa mendatang.

$\mathrm{H}_{5}$ : Customer satisfaction berpengaruh terhadap repurchase intention pada DBD Powder Medan.

\section{Hubungan Brand Awareness dengan} Repurchase Intention yang dimediasi oleh

\section{Customer satisfaction}

Berdasarkan hasil penelitian Ilyah, et.al (2020), Tarigan dan Atika (2020) dan Izzudin dan Novandariri (2018), dapat disampaikan bahwa keberadaan kesadaran merek atas suatu produk yang kuat dalam pandangan konsumen dengan diikuti kepuasan konsumen yang dapat diberikan oleh perusahaan kepada konsumen maka hal ini dapat menumbuhkan dan mendorong niat dalam memotivasi diri konsumen untuk melaksanakan belanja kembali terhadap produk perseroan yang sebelumnya telah pernah dilakukan dan digunakan untuk pemenuhan kebutuhan. Oleh sebab itu, kemauan dan keinginan konsumen unutk membeli kembali produk perusahaan tu tergantung dari seberapa besar kesadaran dan keyakinan yang dimiliki konsumen atas merek tersebut dan sampai sejauh mana konsumen memperoleh kepuasan setelah menggunakan produk tersebut.
$\mathrm{H}_{6}$ : Brand awarenss berpengaruh terhadap repurchase intention yang dimediasi oleh customer satisfaction pada DBD Powder Medan.

\section{Hubungan Percieved quality dengan} Repurchase Intention yang dimediasi oleh Customer satisfaction

Mengarak ke penelitian yang dilaksanakan oleh Wijaksono \& Ali (2019), Hidayah dan Anjarwati (2018), dan Arifin, et.al (2016), dapat disampaikan bahwa konsumen yang mempunyai persepsi kualitas yang baik dan kuat atas produk perusahaan maka keinginan untuk membeli kembali produk tersebut akan semakin besar. Hal ini akan diperkuat oleh kepuasan konsumen yang didapatnya dari perusahaan saat menggunakan produk tersebut sehingga konsumen tidak menemukan kekecewaan selama mengkonsumsi produk untuk kebutuhan hidup sehari-hari. Konsumen yang merasakan dan mendapatkan kepuasan dengan optimal dari produk perusahaan saat menggunakannya maka hal ini dapat memperkuat diri konsumen untuk secara terus menerus menggunakan produk tersebut untuk mencukupi keperluan dirinya secara berkala di masa mendatang. Semakin besar kepuasan yang dirasakan oleh konsumen saat menggunakan produk perusahaan maka semakin baik persepsi kualitas dalam pikiran 
konsumen sehingga hal ini dapat memperkuat diri konsumen untuk terus menerus melakukan pembelian ulang terhadap produk perusahaan baik jangka pendek maupun jangka panjang.

$\mathrm{H}_{7}$ : Percieved quality berpengaruh terhadap repurchase intention yang dimediasi oleh customer satisfaction pada DBD Powder Medan.

\section{Metode Penelitian}

Riset yang dipergunakan yaitu penelitian kausal dengan paradigma kuantitatif. Mengacu pendapat Siregar (2014:16), penelitian kausal adalah bagian penelitian yang dilaksanakan dan digunakan dalam menguji dan mendapatkan pengetahuan sampai sejauh mana kaitan antar variabel yang lain baik satu atau lebih. Penelitian ini dilakukan pada DPD Powder Medan. Populasi yang dipakai adalah pelanggan yang datang dan berbelanja produk perusahaan dengan rata-rata perbulan sebanyak 3.250 konsumen. Metode pengambilan sampel yaitu dengan menggunakan sampel acak, sehingga tiap konsumen mempunyai oportunitas yang sama untuk dipilih sebagai responden dalam penelitian. Rumus pengambilan sampel penelitian adalah rumus slovin.
Riset ini mempergunakan teknik kuesioner dalam mengumpulkan data, angket/kuesioner merupakan pengumpulan data dengan memberikan kuesioner secara tatap muka dengan responden yaitu konsumen yang datang dan membeli produk di DPD Powder Medan. Dalam kuesioner yang berisi pernyataan mengenai masalah yang sedang diteliti diantaranya brand awareness, perceived quality, customer satisfaction dan repurchase intention.

Teknik analisis data yang dipergunakan dalam riset yang dilakukan mencakup uji kualitas data, uji asumsi klasik, uji analisis jalur, uji sobel tes dan uji hipotesis.

\section{Hasil Penelitian dan Pembahasan}

\subsection{Hasil Penelitian}

\section{Uji Asumsi Klasik Sub Struktur I}

Tabel 1 Hasil Uji Kolmogorov-Smirnov Test I

One-Sample Kolmogorov-Smirnov Test

\begin{tabular}{|ll|r|}
\hline & & $\begin{array}{c}\text { Unstandardized } \\
\text { Residual }\end{array}$ \\
\hline $\mathrm{N}$ & Mean & 97 \\
Normal & Std. & 1.53326331 \\
& Deviation & .0000000 \\
Most Extreme & Absolute & .079 \\
Differences & Positive & -.068 \\
& Negative & .782 \\
Kolmogorov-Smirnov Z & .574 \\
\hline Asymp. Sig. (2-tailed)
\end{tabular}

Sumber: Data diolah SPSS, 2021 
Vol. 2 No. 2 Bulan Oktober-Maret 2022

Hasil di atas menunjukkan keluaran pengujian Kolmogorov Smirnov mempunyai nilai signifikansi (Asymp. Sig.2-tailed) yaitu 0,574 sehingga diketahui nilai 0,574>0,05 maka diartikan bahwa nilai residual memiliki distribusi secara normal dan mencukupi asumsi normalitas.

Tabel 2. Hasil Uji Multikolinearitas I

\begin{tabular}{|llc|}
\multicolumn{3}{c|}{ Coefficients } \\
\multicolumn{3}{|c|}{ Collinearity } \\
& \multicolumn{2}{c|}{ Statistics } \\
\cline { 2 - 3 } Voler \\
Variabel & ance & VIF \\
\hline Brand Awareness_X1 & .355 & 2.817 \\
Perceived Quality_X2 & .355 & 2.817 \\
\hline
\end{tabular}

Sumber: Data diolah SPSS, 2021

Hasil di atas menunjukkan variabel brand awareness dan perceived quality menunjukkan nilai tolerance $>0,1$ dan nilai VIF < 10, sehingga dapat disimpulkan model regresi tidak terjadi gejala multikolinearitas. Artinya bahwa antara variabel bebas (brand awareness dan perceived quality) tidak terdapat korelasi satu sama lain.

Tabel 3 Hasil Uji Glejser

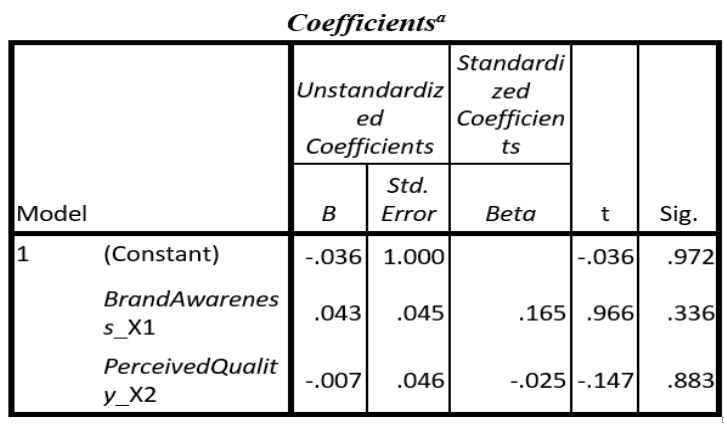

a. Dependent Variable: Abs_res sumber: data diolah SPSS, 2021

Hasil di atas menunjukkan variabel brand awareness mempunyai nilai sig. 0,336, variabel perceived quality sig. 0,883. oleh karena itu, dapat disampaikan bahwa brand awareness dan perceived quality mempunyai nilai sig $>0,05$ dapat tarik kesimpulan bahwa model regresi yang dibuat tidak terjadi gejala heteroskedastisitas, maknanya bahwa variabel pengganggu pada penelitian yang dilakukan tidak ditemukan.

\section{Uji Asumsi Klasik Sub Struktur II}

Tabel 4. hasil uji Kolmogorov-smirnov Test II

11

One-Sample Kolmogorov-Smirnov Test

\begin{tabular}{|c|c|c|}
\hline & & $\begin{array}{c}\text { Unstandardized } \\
\text { Residual }\end{array}$ \\
\hline \multicolumn{2}{|l|}{$\mathrm{N}$} & 97 \\
\hline \multirow{2}{*}{$\begin{array}{l}\text { Normal } \\
\text { Parameters }\end{array}$} & Mean & .0000000 \\
\hline & $\begin{array}{l}\text { Std. } \\
\text { Deviation }\end{array}$ & 1.30349526 \\
\hline \multirow{3}{*}{$\begin{array}{l}\text { Most Extreme } \\
\text { Differences }\end{array}$} & Absolute & .050 \\
\hline & Positive & .035 \\
\hline & Negative & -.050 \\
\hline \multicolumn{2}{|c|}{ Kolmogorov-Smirnov Z } & .491 \\
\hline \multicolumn{2}{|c|}{ Asymp. Sig. (2-tailed) } & 969 \\
\hline
\end{tabular}

Hasil di atas menunjukkan pengujian Kolmogorov Smirnov mempunyai nilai (Asymp. Sig.2-tailed) yaitu 0,969 sehingga diketahui nilai 0,969>0,05 maka ditarik simpulan bahwa nilai residual memiliki distribusi secara normal serta sesuai syarat asumsi normalitas. 
Vol. 2 No. 2 Bulan Oktober-Maret 2022

Tabel 5 HasilUji Multikolinearitas II Coefficients

\begin{tabular}{|lll|}
\hline & \multicolumn{2}{c|}{ Collinearity Statistics } \\
\cline { 2 - 3 } \multicolumn{1}{c}{ Variabel } & Tolera & \\
& nce & VIF \\
\hline Brand Awareness_X1 & .344 & 2.910 \\
Perceived Quality_X2 & .162 & 6.185 \\
Customer Satisfaction Y1 & .187 & 5.360 \\
\hline
\end{tabular}

Sumber: Data diolah SPSS, 2021

Hasil di atas menunjukkan bahwa unutk variabel brand awareness, perceived quality dan customer satisfaction menunjukkan nilai tolerance $>0,1$ dan nilai $\mathrm{VIF}<10$, sehingga dapat disimpulkan model regresi tidak terjadi gejala multikolinearitas. Artinya bahwa antara variabel bebas (brand awareness, perceived quality dan customer satisfaction) tidak terdapat korelasi satu sama lain.

\section{Tabel 6. Hasil Uji Glejser II}

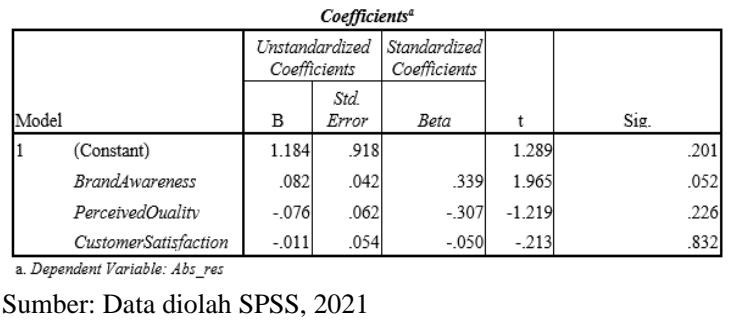

Tabel di atas menunjukkan bahwa untuk variabel brand awareness mempunyai nilai sig. 0,052, variabel perceived quality dengan nilai signifikan 0,226 dan customer satisfaction dengan nilai signifikan 0,832 . Dengan demikian, dapat disampaikan bahwa brand awareness, perceived quality dan customer satisfaction mempunyai nilai sig > 0,05 disimpulkan bahwa model regresi tidak terjadi gejala heteroskedastisits, artinya bahwa tidak ada variabel pengganggu pada penelitian yang dilakukan.

\section{Persamaan Analisis Jalur}

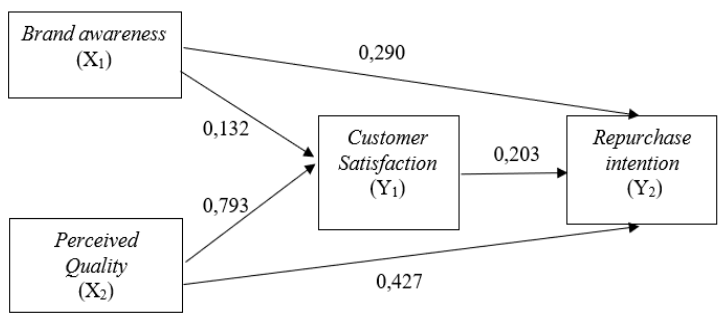

Sumber: Data diolah SPSS, 2021

\section{Gambar 1 Persamaan Analisis Jalur}

Berdasarkan gambar di atas berikut ini dapat dijabarkan mengenai persamaan analisis jalur dari variabel independen (brand awareness dan perceived quality) terhadap variabel dependen (repurchase intention) dimediasi oleh customer satisfaction sebagai berikut:

1) Pengaruh Brand Awareness terhadap Repurchase Intention yang dimediasi oleh Customer Satisfaction.

Didasarkan pada hasil hitungan didapati nilai pengaruh langsung sebesar 0,290 dan pengaruh tidak langsung sebesar 0,027 yang memiliki arti nilai pengaruh tidak langsung lebih kecil dibandingkan nilai pengaruh langsung, hasil ini memberikan petunjuk bahwa secara tidak langsung customer satisfaction memiliki pengaruh tidak signifikan terhadap 
repurchase intention. Berarti bahwa variabel customer satisfaction $\left(\mathrm{Y}_{1}\right)$ tidak memediasi secara signifikan pengaruh brand awareness $\left(\mathrm{X}_{1}\right)$ terhadap repurchase intention $\left(\mathrm{Y}_{2}\right)$ sehingga hipotesis penelitian $\mathrm{H}_{6}$ ditolak.

2) Pengaruh Perceived Quality terhadap Repurchase Intention yang dimediasi oleh Customer Satisfaction

Dilandaskan pada hasil hitungan didapatkan bahwa angka pengaruh langsung sebesar 0,427 dan pengaruh tidak langsung sebesar 0,161 yang memiliki makna bahwa nilai pengaruh tidak langsung $(0,161)<$ nilai pengaruh langsung $(0,427)$, hasil ini memberikan petunjukk bahwa secara tidak langsung customer satisfaction memiliki pengaruh tidak signifikan terhadap repurchase intention. Bermakna variabel customer satisfaction $\left(\mathrm{Y}_{1}\right)$ tidak memediasi secara signifikan pengaruh perceived quality $\left(\mathrm{X}_{2}\right)$ terhadap repurchase intention $\left(\mathrm{Y}_{2}\right)$ sehingga hipotesis penelitian $\mathrm{H}_{7}$ ditolak.

\section{Persamaan Regresi Linear Berganda I}

Tabel 7 Hasil Regresi Linear berganda I

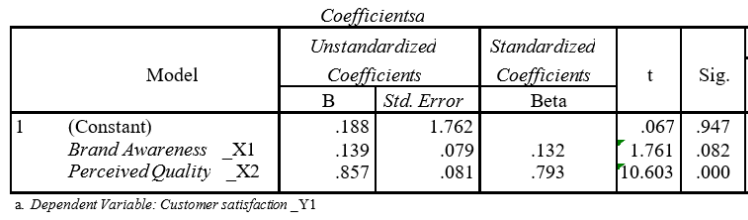

Sumber: Data diolah SPSS, 2021
Berdasarkan tabel di atas maka dapat disajikan persamaan regresi linear berganda yaitu $\mathrm{Y}_{1}=0,188+0,139 \mathrm{X}_{1}+$ $0,857 \mathrm{X}_{2}$. Berikut ini dapat dijabarkan mengenai hasil pengujian regresi linear berganda sebagai berikut:

1) Nilai konstanta (a) sebesar 0,188 dan bernilai positif, artinya dapat meningkatkan customer satisfaction sebesar 0,188 dengan asumsi variabel brand awarenss dan perceived quality mempunyai nilai koefsien nol.

2) Variabel brand awarenss memiliki angka koefisien 0,139 dan bernilai positif, maknanya bila terjadi kenaikan satu poin pada brand awarenss maka daapt meningkatkan customer satisfaction sebesar 0,139.

Variabel perceived quality memiliki nilai koefisien 0,857 dan bernilai positif, artinya bila terjadi kenaikan satu poin pada perceived quality maka akan meningkatkan customer satisfaction sebesar 0,857 .

\section{Persamaan Regresi Linear Berganda II} Tabel 8 Hasil Regresi Linear berganda II

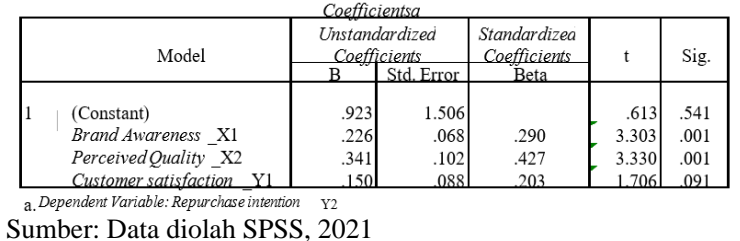


Berdasarkan tabel di atas maka dapat disajikan persamaan regresi linear berganda yaitu $\mathrm{Y}_{2}=0,923+0,226 \mathrm{X}_{1}+$ $0,341 \mathrm{X}_{2}+0,150 \mathrm{Y}_{1}$. Berikut ini dapat dijabarkan mengenai hasil pengujian regresi linear berganda sebagai berikut:

1) Nilai konstanta (a) sebesar 0,923 dan bernilai positif, artinya dapat meningkatkan repurchase intention sebesar 0,923 dengan asumsi variabel brand awarenss, perceived quality dan customer satisfaction mempunyai nilai koefsien nol.

2) Variabel brand awarenss mempunyai nilai koefisien 0,226 dan bernilai positif, artinya bila terjadi kenaikan satu poin pada brand awarenss maka daapt meningkatkan repurchase intention sebesar 0,226.

3) Variabel perceived quality mempunyai nilai koefisien 0,341 dan bernilai positif, artinya bila terjadi kenaikan satu poin pada perceived quality maka daapt meningkatkan repurchase intention sebesar 0,341 .

Variabel customer satisfaction memiliki nilai koefisien 0,150 dan bernilai positif, artinya bila terjadi kenaikan satu poin pada customer satisfaction maka daapt meningkatkan repurchase intention sebesar 0,150 .

\section{Hasil Uji Hipotesis I}

\section{Tabel 9. Hasil Uji Parsial I}

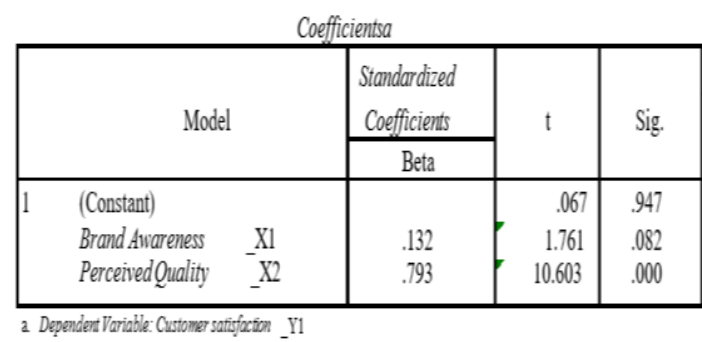

Sumber: Data diolah SPSS, 2021

Jumlah sampel penelitian sebanyak n $=97$ responden sehingga diperoleh nilai $t_{\text {tabel }}$ $=1,660$ pada signifikan 0,05. Berikut ini dapat dijabarkan mengenail hasil pengujian parsial sebagai berikut:

a) Variabel brand awareness menunjukkan terdapat pengaruh positif tetapi tidak signifikan terhadap customer satisfaction (nilai $t_{\text {hitung }}>t_{\text {tabel, }}$ $1,761>1,660$ pada signifikan $0,082>$ 0,05) sehingga disimpulkan bahwa hipotesis penelitian $\mathrm{H}_{1}$ diterima.

b) Variabel perceived quality menunjukkan terdapat pengaruh positif tetapi tidak signifikan terhadap customer satisfaction (nilai $t_{\text {hitung }}>\mathrm{t}_{\text {tabel, }}$, $10,603>1,660$ pada signifikan $0,000<$ 0,05) sehingga disimpulkan bahwa hipotesis penelitian $\mathrm{H}_{2}$ diterima. 
Vol. 2 No. 2 Bulan Oktober-Maret 2022

Hasil Uji Hipotesis II

Tabel 10. Hasil Uji Parsial II

\begin{tabular}{|c|c|c|c|c|c|}
\hline \multicolumn{6}{|c|}{ Coefficientsa } \\
\hline & \multirow{2}{*}{\multicolumn{2}{|c|}{ Model }} & $\begin{array}{c}\text { Standardized } \\
\text { Coefficients }\end{array}$ & \multirow[t]{2}{*}{$t$} & \multirow[t]{2}{*}{ Sig. } \\
\hline & & & Beta & & \\
\hline \multirow[t]{3}{*}{1} & (Constant) & & & .619 & .538 \\
\hline & Brand Awareness & $\mathrm{Xl}$ & .317 & 3.630 & .000 \\
\hline & Perceived Quality & X2 & .588 & 6.733 & .000 \\
\hline
\end{tabular}

Sumber: Data diolah SPSS, 2021

Berikut ini dapat dijabarkan mengenail hasil pengujian parsial sebagai berikut:

a) Variabel brand awareness menunjukkan terdapat pengaruh positif dan signifikan terhadap repurchase intention (nilai $t_{\text {hitung }}>\mathrm{t}_{\text {tabel }}, 3,630>$ 1,660 pada signifikan $0,000>0,05)$ sehingga disimpulkan bahwa hipotesis penelitian $\mathrm{H}_{3}$ diterima.

b) Variabel perceived quality menunjukkan terdapat pengaruh positif tetapi tidak signifikan terhadap repurchase intention (nilai $t_{\text {hitung }}>\mathrm{t}_{\text {tabel }}$, $6,773>1,660$ pada signifikan $0,000<$ 0,05) sehingga disimpulkan bahwa hipotesis penelitian $\mathrm{H}_{4}$ diterima.

\section{Hasil Uji Hipotesis III}

\section{Tabel 11. Hasil Uji Parsial III}

\begin{tabular}{|c|c|c|c|c|}
\hline \multicolumn{5}{|c|}{ Coefficientsa } \\
\hline & \multirow{2}{*}{ Model } & $\begin{array}{l}\text { Standardized } \\
\text { Coefficients }\end{array}$ & \multirow{2}{*}{$t$} & \multirow{2}{*}{ Sig. } \\
\hline & & Beta & & \\
\hline 1 & $\begin{array}{l}\text { (Constant) } \\
\text { Customer satisfaction } \mathrm{Y} 1\end{array}$ & .810 & $\begin{array}{r}3.287 \\
13.451 \\
\end{array}$ & .001 \\
\hline
\end{tabular}

a. Dependent Variable: Repurchaseintention $\mathrm{Y}_{2}$

Sumber: Data diolah SPSS, 2021
Hasil di atas memberikan petunjuk bahwa customer satisfaction berpengaruh positif dan signifikan terhadap repurchase intention pada DBD Powder Medan (nilai $t_{\text {hitung }}>\mathrm{t}_{\text {tabel }}, 13,451>1,660$ pada signifikan $0,000<0,05)$ sehingga dapat ditarik simpulan bahwa hipotesis penelitian $\mathrm{H}_{5}$ diterima

\subsection{Pembahasan}

Hipotesis I (H1) Pengaruh Brand Awareness terhadap Customer Satisfaction pada DBD Powder Medan

Hasil penelitian pada tabel 9 dengan nilai $t_{\text {hitung }}>\mathrm{t}_{\text {tabel }}, 1,761>1,660$ pada signifikan 0,082 >0,05 menunjukan bahwa kesadaran merek berpengaruh tetapi tidak signifikant terhadap kepuasan konsumen. dapat disampaikan bahwa terdapat kesamaan antara penelitian yang dilakukan dengan penelitian terdahulu mengenai sampai sejauh mana keberadaan brand awareness yang dapat dilakukan oleh pimpinan perusahaan agar dapat menumbuhkan kesadaaran merek dalam pikiran konsumen sehingga konsumen yang telah mengenal merek produk perusahaan maka dirinya akan teringat untuk membeli dan menggunakan produk minuman perusahaan. 
Hipotesis II $\left(\mathrm{H}_{2}\right)$ Pengaruh Perceived Quality terhadap Customer Satisfaction pada DBD Powder Medan

Hasil penelitian pada tabel 9 dengan nilai $\mathrm{t}_{\text {hitung }}>\mathrm{t}_{\text {tabel }}, 10,603>1,660$ pada signifikan $0,000<0,05$ menunjukan bahwa persepsi kualitas berpengaruh signifikant terhadap kepuasan konsumen. Dengan demikian dapat dikemukakan bahwa penting bagi perusahaan dan seluruh jajaran pegawainya untuk memberikan pelayanan yang optimal dan diupayakan tidak membuat konsumen merasa kecewa. Oleh sebab itu, hal ini sangat penting untuk dapat diperhatikan dan dipertahankan oleh pemilik perusahaan agar kelangsungan usaha dapat berjalan lancar dan unggul dalam menghadapi persaingan di tengah persaingan usaha semakin kompetitor.

\section{Hipotesis III ( $\left.\mathrm{H}_{3}\right)$ Pengaruh Brand} Awareness terhadap Repurchase Intention pada DBD Powder Medan

Hasil penelitian pada tabel 10 dengan nilai $t_{\text {hitung }}>t_{\text {tabel }}, 3,630>1,660$ pada signifikan $0,000>0,05)$ menunjukan bahwa kesadaran merek dalam diri konsumen berpengaruh signifikan terhadap pembelian ulang dari produk yang dijual perusahaan. Dengan demikian, dapat disampaikan bahwa untuk mendorong konsumen agar membeli kembali produk perusahaan yang pernah dibelinya maka pimpinan perlu melakukan upaya untuk memberikan kesadaran secara terus menerus mengenai merek dan manfaat produk perusahaan kepada tiap konsumen dan konsistensi ini sangat penting.

\section{Hipotesis IV ( $\left.\mathbf{H}_{4}\right)$ Pengaruh Perceived Quality terhadap Repurchase Intention pada DBD Powder Medan}

Hasil penelitian pada tabel 10 dengan nilai $t_{\text {hitung }}>\mathrm{t}_{\text {tabel }}, 6,773>1,660$ pada signifikan $0,000<0,05$ ) menunjukan bahwa persepsi kualitas pada pandangan konsumen berpengaruh signifikan terhadap pembelian kembali. . Dengan demikian, dapat disampaikan bahwa untuk membuat konsumen agar mau membeli kembali produk perusahaan maka pegawai perusahaan haruslah dapat memberikan pelayanan yang terbaik bagi konsumen sehingga tidak menimbulkan salah paham ataupun kekecewaan saat awal pertama membeli produk perusahaan.

\section{Hipotesis V (H5) Pengaruh Customer} Satisfaction terhadap Repurchase Intention pada DBD Powder Medan

Hasil penelitian pada tabel 11 dengan nilai $t_{\text {hitung }}>\mathrm{t}_{\text {tabel}}, \quad 13,451>1,660$ pada signifikan $0,000<0,05$ menunjukan bahwa kepuasan konsumen yang diperoleh dari perusahaan dapat berpengaruh signifikan terhadap pembelian ulang produk 
perusahaan. Dengan pandangan demikian maka konsumen tidak akan mudah terpengaruh dengan produk dari pesaingnya meskipun produk tersebut telah cukup lama dikenal oleh masyarakat. Dengan kepuasan yang telah dapat diberikan oleh perusahaan dengan baik maka hal ini harus dapat dipertahankan dengan sebaik mungkin agar tidak terjadi penurunan yang dapat merugikan aktivitas perusahaan dalam memasarkan produk di masa mendatang.

\section{Hipotesis VI ( $\left.\mathrm{H}_{6}\right)$ Pengaruh Brand} Awareness terhadap Repurchase Intention yang diintervening oleh Customer Satisfaction pada DBD Powder Medan

Hasil penelitian pada gambar 1 menunjukan bahwa nilai pengaruh langsung sebesar 0,290 dan pengaruh tidak langsung sebesar 0,027 yang berarti bahwa nilai pengaruh tidak langsung $(0,027)<$ nilai pengaruh langsung $(0,290)$, hasil ini menunjukkan bahwa customer satisfaction $\left(\mathrm{Y}_{1}\right)$ tidak memediasi secara signifikan pengaruh brand awareness $\left(\mathrm{X}_{1}\right)$ terhadap repurchase intention $\quad\left(\mathrm{Y}_{2}\right)$. Dengan demikian konsumen yang membeli produk perusahaan terdiri dari berbagai tipe dan perbedaan yang disertai dengan pengetahuan konsumen yang telah semakin berkembang dari waktu ke waktu.
Hipotesis VII $\left(\mathrm{H}_{7}\right)$ Pengaruh Perceived Quality terhadap Repurchase Intention yang di interveing oleh Customer Satisfaction pada DBD Powder Medan

Hasil penelitian pada gambar 1 menunjukan bahwa nilai pengaruh langsung sebesar 0,427 dan pengaruh tidak langsung sebesar 0,161 yang berarti bahwa nilai pengaruh tidak langsung $(0,161)<$ nilai pengaruh langsung $(0,427)$, artinya variabel customer satisfaction $\left(\mathrm{Y}_{1}\right)$ tidak memediasi secara signifikan pengaruh perceived quality $\left(\mathrm{X}_{2}\right)$ terhadap repurchase intention $\left(\mathrm{Y}_{2}\right)$. Dengan demikian konsumen menjadi tidak nyaman saat berinteraksi dengan perusahaan dalam hari-hari berikut ini konsumen tidak berminat untuk membeli ulang produk perusahaan, akan tetapi dirinya akan lebih memilih membeli produk dari pesaignnya karena berharap bahwa pelayanan yang akan diberikan oleh pegawainya akan jauh lebih baik dari perusahaan sebelumnya.

\section{Kesimpulan dan Saran}

\subsection{Kesimpulan:}

Berdasarkan hasil pengujian statistik yang telah dilakukan dan disampaikan di atas, maka berikut ini beberapa simpulan yang dapat disampaikan sebagai berikut:

1. Secara parsial menunjukkan bahwa brand awareness berpengaruh positif 
Vol. 2 No. 2 Bulan Oktober-Maret 2022

tetapi tidak signifikan terhadap customer satisfaction, sedangkan perceived quality berpengaruh positif dan signifikan terhadap customer satisfaction. Sementara itu, brand awareness dan perceived quality secara parsial pengaruh signifikan terhadap repurchase intention, dan customer satisfaction pengaruh positif dan signifikan terhadap repurchase intention di DBD Powder Medan.

2. Secara simultan menunjukkan bahwa brand awareness dan perceived quality serempak pengaruh signifikan pada customer satisfaction. Sementara itu, brand awareness, perceived quality dan customer satisfaction bersama-sama pengaruh positif dan signifikan terhadap repurchase intention di DBD Powder Medan.

3. Brand awarenss dan perceived quality mempunyai korelasi yang sangat kuat terhadap customer satisfaction di DBD Powder dan bersarnya persentase kepuasan konsumen dapat dijelaskan oleh Brand awarenss dan perceived quality sebesar $81,3 \%$ dan sisanya $19,7 \%$ dapat dijelaskan oleh variabel lainnya yang tidak diteliti seperti promosi, harga, pelayanan dan sebagainya. Sementara itu, brand awarenss, perceived quality dan customer satisfaction mempunyai korelasi yang sangat kuat terhadap repurchase intention di DBD Powder Medan dan besarnya persentase sebesar $74,5 \%$ dan sisanya $25,5 \%$ dapat dijelaskan oleh variabel lainnya yang tidak diteliti.

\subsection{Saran:}

\section{DAFTAR PUSTAKA}

Aquinia, A., and Soliha Euis. (2020). The Effect of Brand Equity dimension on Repurchase Intention. DIJB: Diponegoro International Journal of Business. Vol.3. No.2. Page: 97-103.pISSN: 2580-4987; e-ISSN: 2580-4995.

Arifin, S., Yusof, J.M., Putit, L., and Shah, Mohd.I.A. (2016). Factors Influensing Perceived Quality and Repurchase Intention. Procedia Economia and Financen 37. Page: 391-396.

Bimantari, C. (2018). Pengaruh Kesadaran Merek, Kualitas yang dirasakan, dan Sikap Merek pada Niat Beli Biskuit Orea di Surabaya. Journal Business and Banking. Vol.8. No.2. November 2018-April 2019. ISSN: 2088-7841. Hal: 195-212

Eliasari, P.R.A., dan Sukaatmadja, I Putu Gde. (2017). Pengaruh Brand Awareness terhadap Purchase Intention dimediasi oleh Perceived Quality dan Brand Loyalty. E-Jurnal Manajemen Unud. Vol.6. No12. Hal: 6620-6650. ISSN: 2302-8912. 
Hidayah, Nur., dan Anjarwati, A.L. (2018). Pengaruh Perceived Quality terhadap Niat Beli Ulang dengan Kepuasan Sebagai Variabel Intervening (Studi pada Pelanggan The Botol Sosro di Surabaya Timur). Jurnal Ilmu Manajemen. Vol.6. No.1.

Ilyas, G.B., Rahmi, S., Tamsah, H., dan Munir, A.R. (2020). Reflective Model of Brand Awareness on Repurchase Intention and Costumer Statisfication. Journal of Asian Finance, Economics and Business Vol. 7. No 9. Page: 427438. Print ISSN: 2288-4637 / Online ISSN : 2288-4645.

Izzudin, M.S., and Novandari, W. (2018). The Effect of Perceived Quality, Brand Image on Customer Satisfaction and Brand Awareness Toward Repurchase Intention. Journal of Reseach in Management. Vol.1. No.3. Page: 3243.

Tarigan, Y., and Atika, N. (2020). The Effect of Customer Satisfaction on Interest Buy Online on Website Lazada. JABA (Journal of Appied Business Administration). E-ISSN: 25489909.

Wijaksono, D., \& Ali, H. (2019). Model Repurchase Intention: Analsis of Brand Awareness, Perceived Quality, Brand Association and Brand Loyalty (Case Study Private Label on Store Alfamidi in Tangerang. Saudi Journal of Humanities and Social Sciences. Vol.4. Issue: 5. May. ISSN 24156256 (Print). ISSN 2415-6248 (Online). Page: 371-380. 